\title{
KONTROL KECEPATAN MESIN PEMUTAR GERABAH DENGAN KONTROL LOGIKA FUZZY-TSK BERBASIS MIKROKONTROLLER ATMEGA 8535
}

\author{
${ }^{1}$ Rahma Nur Amalia, ${ }^{2}$ M.Aziz Muslim, ${ }^{3}$ Erni Yudaningtyas \\ ${ }^{1}$ Politeknik Negeri Malang, Jl.Soekarno Hatta 9 Malang,(0341)404424 \\ ${ }^{2}$ Universitas Brawijaya, J1.Veteran Malang, (0341)551611 \\ ${ }^{3}$ Universitas Brawijaya, Jl.Veteran Malang, (0341)551611 \\ e-mail: rahma.polinema@gmail.com,muh aziz@ub.ac.id, erni@ub.ac.id
}

Receive: 10 Januari $2021 \quad$ Accepted: 05 Februari 2021

\begin{abstract}
The pottery is planned to be rotated by direct current motor (DC motor) that become a new thing for the craftsmen, because they are accustomed to use a manual spinner, which is helped by a leg. This tool is controlled by an ATMEGA 8535 microcontroller and the control method is uding the TakagiSugeno-Kang Fuzzy Logic Controller. Fuzzy logic which is designed has 2 inputs (Err speed \& $\Delta E r r$ speed) and 1 output (PWM). Input setting point is set by pressing the keypad button in the form of digital data, which is then converted to voltage by the ATMEGA 8535 microcontroller. The output of the microcontroller is Pulse Width Modulation (PWM) then used as input for motor drivers. System response testing is carried out on setting point variations, load variations and rule variations. From the data obtained, it shows that the system response is quite good in pursuing the setting point values in various variations, such as setting points, loads and rules. System response for 95 Rpm setpoint, Ess value of $1.31 \%$, Ts when $1 \mathrm{~kg}$ load is $49 \mathrm{~s}$.
\end{abstract}

Keywords: Fuzzy-TSK, Microcontroller ATMEGA 8535, DC Motor

\begin{abstract}
Abstrak
Alat pembuat gerabah yang direncanakan diputar oleh motor arus searah (Motor DC) memang merupakan hal baru bagi para pengrajin, dikarenakan mereka terbiasa menggunakan pemutar manual, yaitu dengan bantuan kaki. Alat ini dikontrol oleh mikrokontroler ATMEGA 8535 dan metode pengaturannya menggunakan kontrol logika Fuzzy Takagi-Sugeno-Kang. Logika fuzzy yang dirancang memiliki 2 input (Err kecepatan \& $\Delta$ Err kecepatan) dan 1 output (PWM). Input setting point dilakukan dengan menekan tombol keypad yang berupa data digital, yang kemudian dikonversi ke tegangan oleh mikrokontroler ATMEGA 8535. Keluaran dari mikrokontroller berupa Pulse Width Modulation (PWM) menjadi masukan untuk penggerak motor (driver motor). Pengujian respon sistem dilakukan terhadap variasi setting point, variasi beban dan variasi rule. Dari data yang diperoleh menunjukkan bahwa respon sistem cukup baik dalam mengejar nilai setting point dalam berbagai variasi yaitu setting point, beban dan rule. Respon sistem untuk setpoint $95 \mathrm{Rpm}$ nilai Ess sebesar 1,31\%, $\mathrm{T}_{\mathrm{s}}$ ketika beban $1 \mathrm{~kg}$ sebesar 49s.
\end{abstract}

Kata Kunci: Fuzzy-TSK, Mikrokontroler ATMEGA 8535, Motor DC

\section{PENDAHULUAN}

Telah menjadi fenomena bahwa kebutuhan manusia akan hal- hal yang bersifat dekoratif sangat banyak digemari. Gerabah adalah salah satu jenis hiasan yang digemari penyuka desain interior. Sampai saat ini penggunaan tenaga manusia sebagai sumber gerak merupakan hal lumrah yang dilakukan oleh para pengrajin untuk membuat gerabah. Padahal jika untuk memenuhi kebutuhan konsumen dalam jumlah yang banyak, 
JT : Jurnal Teknik

P-ISSN: 2302-8734

E-ISSN: 2581-0006

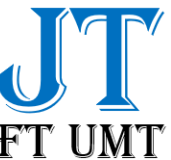

Vol. 10 No. 1 Th. 2021

Halaman : $82-87$

Januari 2021

maka hal tersebut sulit terpenuhi. Maka dari itu, penulis mencoba untuk melakukan analisis dan membuat terobosan baru tentang mesin pemutar gerabah yang nantinya diharapkan akan berguna untuk masyarakat.

Berdasarkan pada penelitian sebelumnya [1], yaitu kontrol kecepatan motor pemutar gerabah menggunakan kontroler Proporsional Integral Diferensial (PID), tetapi memiliki kekurangan yaitu respon yang dicapai masih lambat. Dalam penelitian ini, digunakan kontrol logika Fuzzy, karena kontrol logika Fuzzy merupakan alternatif sistem kendali modern yang mudah, yaitu tidak perlu mencari model matematis dari suatu sistem, tetapi tetap efektif karena memiliki respon keluaran sistem yang stabil. Kontrol logika Fuzzy juga merupakan salah satu kontroler yang redundant atau fault tolerant yang artinya masih dapat bekerja dengan adanya pengurangan beberapa rule, maupun jika terjadi kesalahan-kesalahan kecil dalam pemrogramannya [2]. Perlu diketahui bahwa kelebihan dari kontrol logika fuzzy Takagi- Sugeno-Kang dibandingkan dengan menggunakan kontrol logika fuzzy metode Mamdani adalah dapat menghemat memori mikrokontroler dan lebih cepat di proses oleh mikrokontroler, dikarenakan fungsi keanggotaan keluarannya berupa konstanta atau fungsi linier, sehingga kontrol logika fuzzy Takagi- Sugeno-Kang lebih ringkas dan efisien dalam hal komputasi.

\section{METODE PENELITIAN}

Dalam penelitian dilakukan beberapa tahapan yaitu penentuan fisik alat, pembuatan diagram blok, perancangan mekanik, perancangan perangkat elektrik dan perancangan perangkat lunak. Perancangan alat ini dilakukan secara bertahap dalam bentuk blok, sehingga akan memudahkan dalam analisis pada setiap bloknya maupun secara keseluruhan. Perancangan ini terdiri dari perancangan sistem, perancangan perangkat keras terdiri atas sensor rotary encoder, driver motor, dan rangkaian mikrokontroller, perancangan bentuk mekanik pemutar gerabah, dan perancangan sistem logika fuzzy Takagi-Sugeno-Kang serta implementasinya pada mikrokontroller.

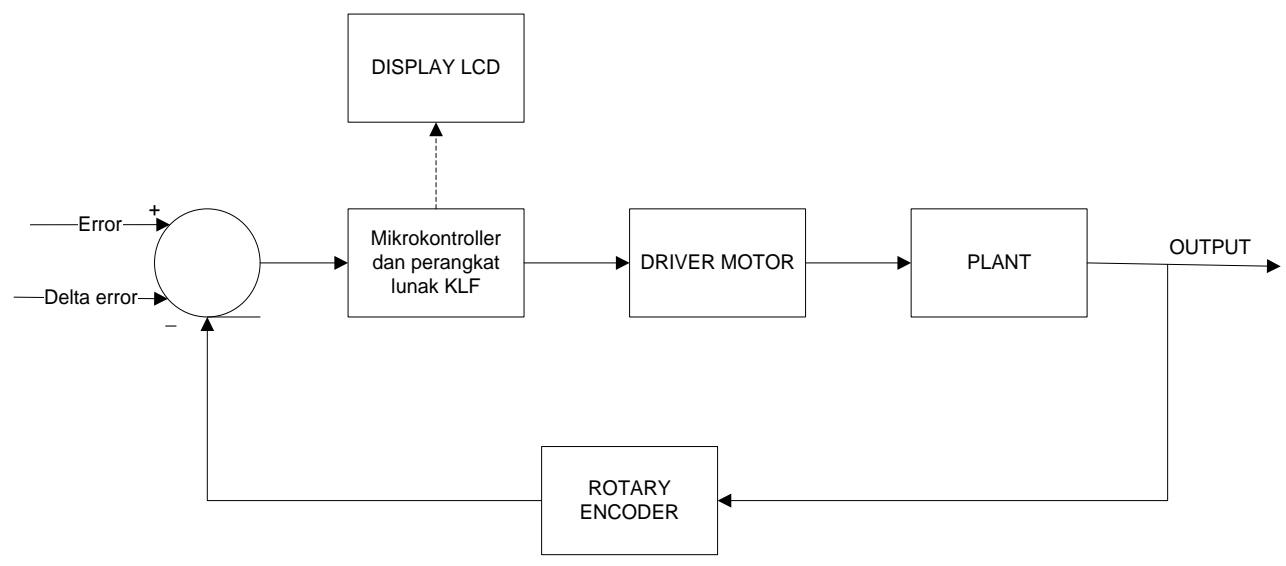

Gambar 1 Gambar Blok Diagram Sistem (Perancangan) 


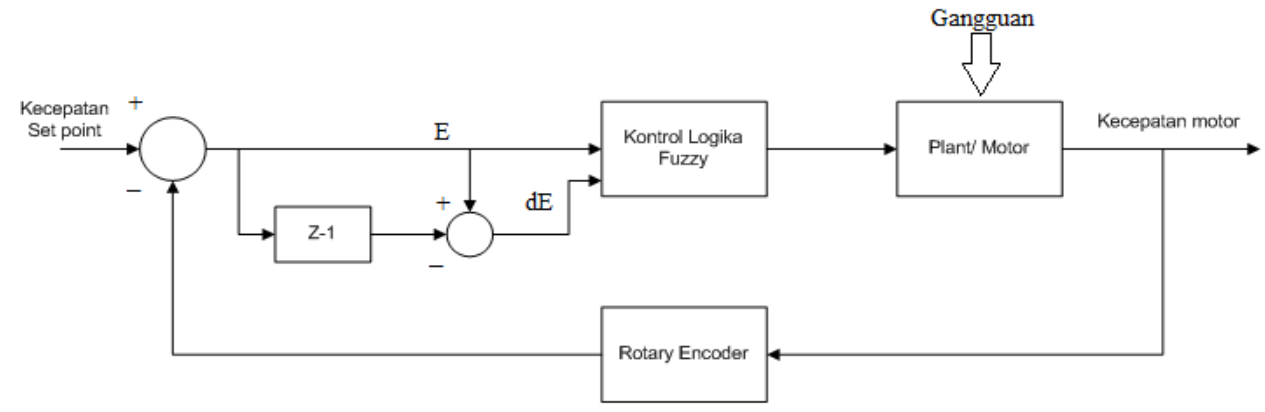

Gambar 2 Blok Diagram Kontrol Logika Fuzzy (Perancangan)

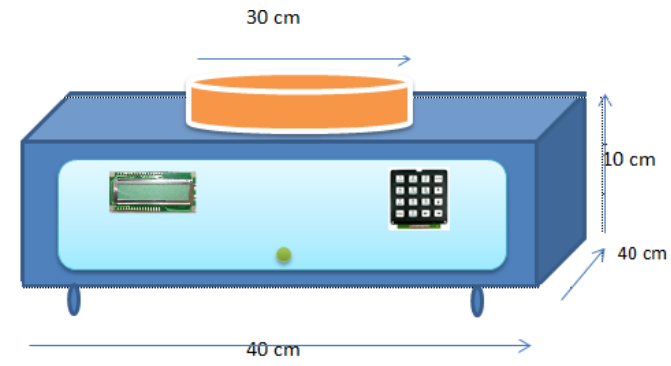

Gambar 3 Desain Rancangan Perangkat Keras

HASIL DAN PEMBAHASAN

Pengujian ini bertujuan untuk mengetahui kemampuan kerja dari perangkat lunak (Kontrol Logika Fuzzy) dan perangkat keras saat diintegrasikan secara bersama- sama. . Pengujian dilakukan dengan merangkaikan seperti pada gambar 5 di bawah, kemudian mengaktifkan semua alat yang telah dirakit, setelah itu mengamati kerja dari sistem tersebut. Dalam pengujian ini, kita memberi masukan setpoint dengan nilai masingmasing $33 \mathrm{rpm}, 52 \mathrm{rpm}, 65 \mathrm{rpm}, 82 \mathrm{rpm}$ dan $95 \mathrm{rpm}$. Setelah itu kita akan melihat respon dari masing- masing setpoint ketika tanpa beban atau dengan beban $1 \mathrm{~kg}, 1,5 \mathrm{~kg}$ dan $2 \mathrm{~kg}$, apakah sudah memenuhi setpoint atau belum.

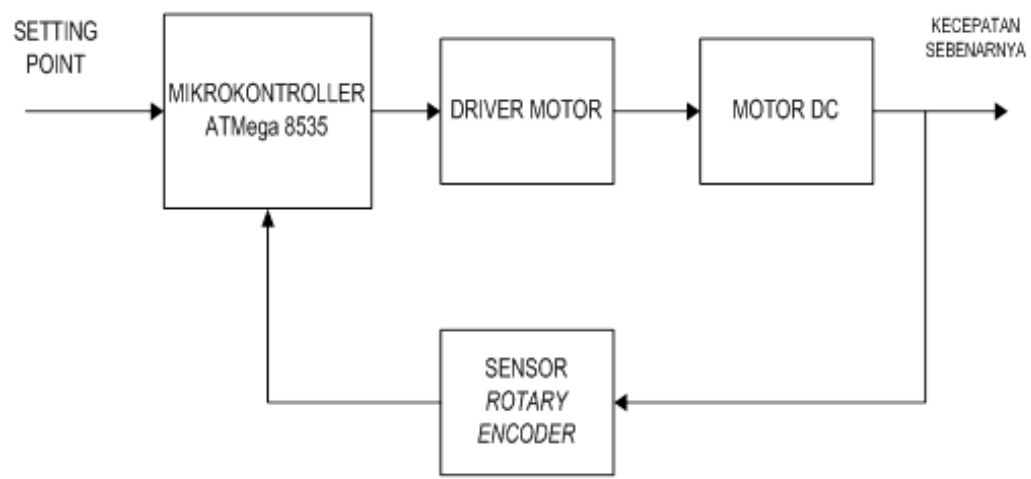

Gambar 4 Blok Diagram Pengujian Sistem Secara Keseluruhan

Pada pengujian kali ini dipilih setpoint dengan kecepatan putar sebesar $65 \mathrm{rpm}$ 
JT : Jurnal Teknik

P-ISSN: 2302-8734

E-ISSN: 2581-0006

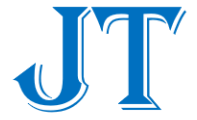

FT UMT
Vol. 10 No. 1 Th. 2021

Halaman : $82-87$

Januari 2021

dengan variasi beban yaitu kondisi tanpa beban, beban $1 \mathrm{~kg}, 1,5 \mathrm{~kg}$ dan $2 \mathrm{~kg}$. Parameter yang diamati yaitu berupa nilai Settling Time (Ts) dan Error Steady State (ess).

- Tanpa Beban

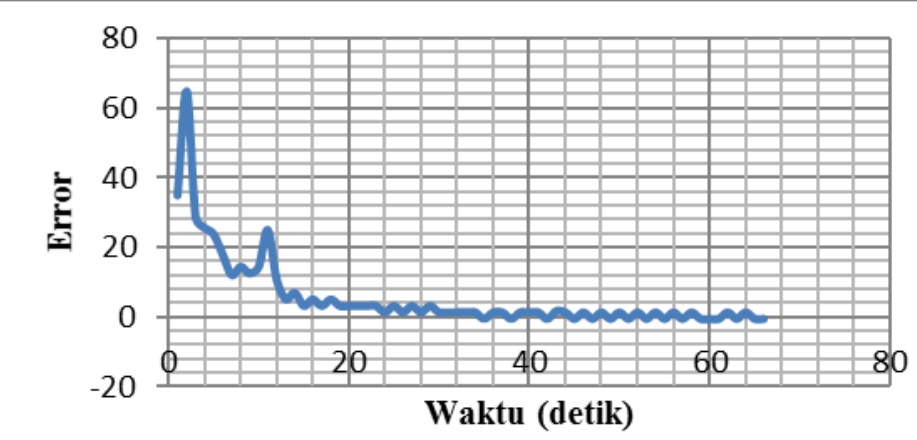

Gambar 5 Grafik Keluaran Error Terhadap Waktu dengan Setpoint 0-65 Rpm Tanpa Beban

Dalam Gambar 5 tersebut, terdapat nilai-nilai ts dan ess sebagai berikut:

$$
\begin{aligned}
& t_{s}=67-0 \\
& t_{s}=67 \mathrm{~s} \\
& \text { ess }=\frac{0,63}{65} \times 100 \%=0,96 \%
\end{aligned}
$$

- Beban $2 \mathrm{Kg}$

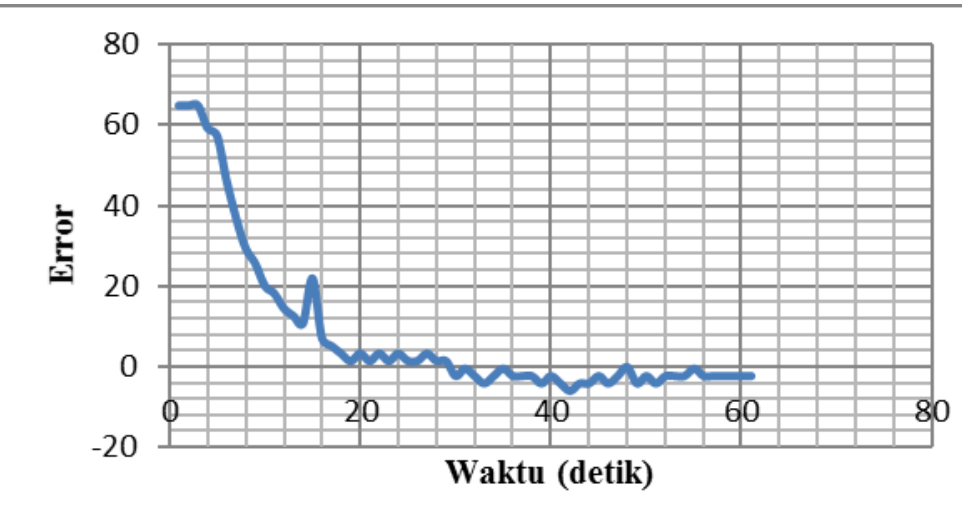

Gambar 6 Grafik Keluaran Error Terhadap Waktu dengan Setpoint 0-65 Rpm Beban $2 \mathrm{Kg}$

Pada Gambar 6 tersebut, terdapat nilai-nilai ts dan ess sebagai berikut:

$$
\begin{aligned}
& >\mathrm{t}_{\mathrm{s}}=61-0 \\
& \mathrm{t}_{\mathrm{s}}=61 \mathrm{~s} \\
& >\text { ess }=\frac{2.5}{65} \times 100 \%=3,84 \%
\end{aligned}
$$


Pada pengujian ini, model pemutar gerabah diberi beban sebesar $2 \mathrm{~kg}$, yang kemudian dapat kita lihat respon dari masing- masing setpoint berupa kecepatan yang didapat dari menekan tombol keypad, yaitu setpoint pertama sebesar $52 \mathrm{rpm}$ dan setpoint kedua sebesar $65 \mathrm{rpm}$, setpoint ketiga sebesar $82 \mathrm{rpm}$, maka respon sistem dengan kontrol logika fuzzy ditunjukkan dalam Gambar 11 di bawah.

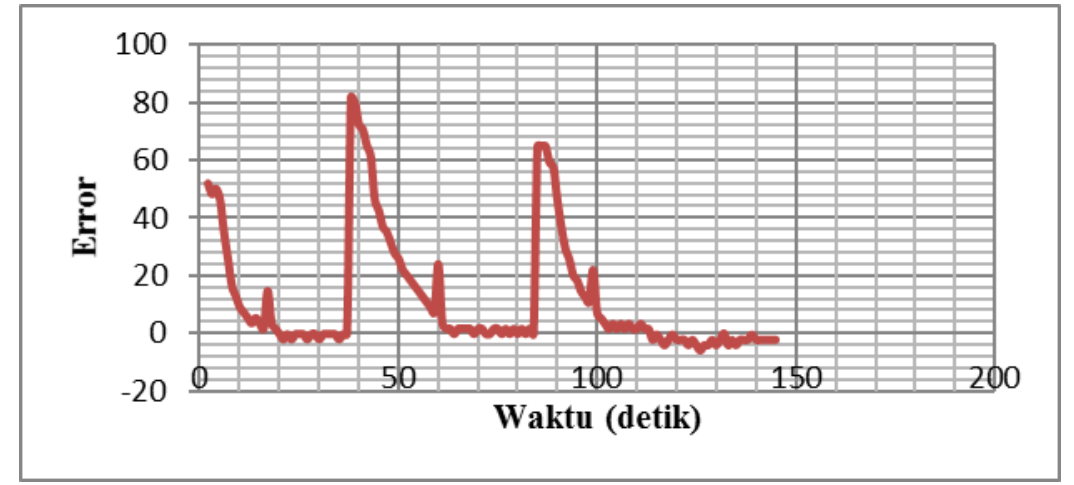

Gambar 6 Grafik Respon Keluaran Sistem dengan Setpoint yang Berbeda- Beda

Tabel 1 Nilai Ts dan Ess pada Masing- Masing Setpoint

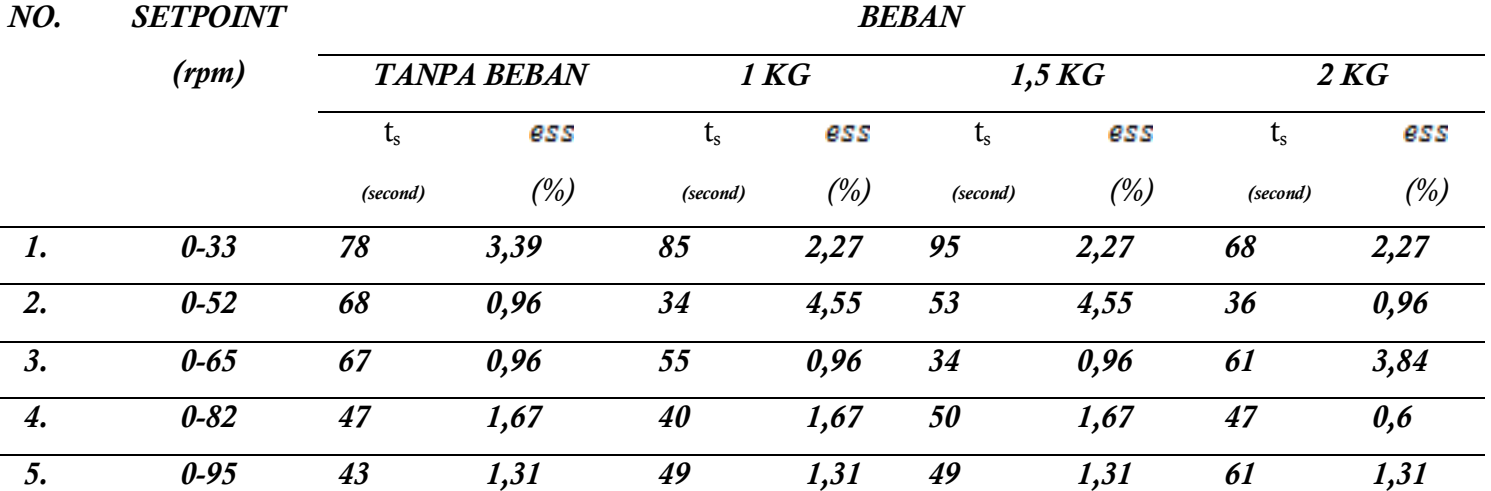

Berdasarkan hasil dari pembacaan nilai ts dan ess dari masing-masing setpoint yang berbeda-beda tersebut, maka dapat dilihat bahwa dengan beban yang bervariasi dihasilkan respon time settiling (ts) yang semakin kecil seiring bertambah besarnya nilai setpoint berupa rpm. Sedangakan nilai semua ess dengan sepoint yang bervariasi didapatkan nilai ess yang memenuhi sesuai standar ilmu kontrol yaitu maksimal berkisar $2 \%-5 \%$.

\section{UCAPAN TERIMAKASIH}

Ucapan terima kasih terutama ditujukan kepada Bapak Muh.Aziz Muslim dan Ibu Erni Yudaningtyas selaku dosen pembimbing saya dan kepada semua rekan-rekan di kampus tercinta Politeknik Negeri Malang yang selalu memberi saya support dan semngat, sekaligus tempat dimana saya mengabdi dan berkontribusi untuk memberikan harapan dan semngat kepada anak didik selaku penerus bangsa. 


\section{SIMPULAN DAN SARAN}

Hasil pengujian terhadap aplikasi kontrol logika fuzzy Takagi-Sugeno-Kang menunjukkan bahwa kontrol logika fuzzy Takagi-Sugeno-Kang dapat digunakan sebagai kontrol kecepatan pada alat pemutar gerabah. Hal tersebut berdasarkan hasil nilai ts dan ess yang memenuhi standar yaitu maksimal berkisar 2\%-5\%. Sehingga dapat disimpulkan juga bahwa sistem ini stabil jika diaplikasikan menjadi sebuah alat yang nantinya benarbenar dapat digunakan dan bermanfaat untuk pengrajin dan masyarakat.

\section{DAFTAR PUSTAKA}

ATMEL. 2007. ATMEGA8535,8-bit AVR microcontroller with 16 kbytes in system programable flash

Fajar. 2007. Aplikasi Logika Fuzzy dalam Optimisasi Produksi Barang Menggunakan Metode Mamdani dan Metode Sugeno

Gerabah. http://jurnal.isidps.ac.id/index.php/artikel/article/view/491(25Juni2012)

Hidayat, Rosidi. "Proses Pembuatan Roda Gigi Payung Pemutar Gerabah",

Irwansetyo." Mengenal dan Memahami Prinsip Dasar Mikrokontroler AVR ATMEGA8535 untuk Simulasi dan Pemodelan Sistem Aplikasi"

Jamsihidi, M.1993. "Fuzzy Logic and Control", New Jersey: Prentice-Hall.

Khasbullah, H. 2011.Kontrol Kecepatan Pemutar Gerabah dengan Kontroller PID Menggunakan Mikrokontroller ATMega 8535. (Skripsi). Malang: Universitas Brawijaya.

Kusumadewi, S. 1997. Neuro Fuzzy Integrasi Sistem Fuzzy dan Jaringan Syaraf. Jakarta: Erlangga.

Murakami, S. and Maeda, M. 1985. Automobile Speed Control System Using a Fuzzy Logic Controller, Amsterdam: North-Holland.

Petrafuz.1999. Sistem Pengembangan Kendali Fuzzy Logic berbasis Mikrokontroler Keluarga MCS51, Prosiding Seminar Nasional Penerapan Teknologi Kendali dan Instrumentasi pada Pertanian.Jakarta: BPPT.

Putra, R. 1999. Implementasi Kendali Fuzzy Logic pada Microcontroller untuk Kendali Putaran Motor DC. (Skripsi). Surabaya: Institut Teknologi Sepuluh November. 